\title{
Prevalence, awareness, treatment and control of hypertension in elderly Chinese
}

\author{
Chang-Sheng Sheng, Ming Liu, Yuan-Yuan Kang, Fang-Fei Wei, Lu Zhang, Ge-Le Li, Qian Dong, \\ Qi-Fang Huang, Yan Li and Ji-Guang Wang
}

We studied the prevalence, awareness, treatment and control of hypertension in an elderly Chinese population. The study subjects (age $\geqslant 60$ years) were recruited from a suburban town of Shanghai from 2006 to 2008. We administered a standardized questionnaire to collect information on medical history, the use of medications and lifestyle. We measured blood pressure three times consecutively using a validated Omron 7051 oscillometric device (Kyoto, Japan) after the subjects had rested for at least $5 \mathrm{~min}$ in the sitting position. We defined hypertension as a blood pressure of at least $140 \mathrm{~mm} \mathrm{Hg}$ systolic or $90 \mathrm{~mm} \mathrm{Hg}$ diastolic or as the use of antihypertensive drugs. The 3949 participants (mean age of 68.3 years) included 2185 $(55.3 \%)$ women, $182(4.6 \%)$ obese subjects (body mass index $\geqslant 30 \mathrm{~kg} \mathrm{~m}^{-2}$ ) and $366(9.3 \%)$ diabetic patients. The prevalence of hypertension was $59.4 \%$. In the 2345 hypertensive patients, the awareness, treatment and control $(<140 / 90 \mathrm{~mm} \mathrm{Hg})$ rates were $72.5 \%, 65.8 \%$ and $24.4 \%$, respectively. In the 1542 treated hypertensive patients, $1196(77.6 \%)$ used fixed-dose combinations of thiazide and reserpine or clonidine $(n=1157,75.0 \%)$ or of an angiotensin receptor blocker and hydrochlorothiazide $(n=1)$ or free combinations $(n=38,2.5 \%)$, and $346(22.4 \%)$ used a monotherapy of short-acting calcium channel blockers $(n=217,14.1 \%)$ or other classes of antihypertensive drugs $(n=129,8.3 \%)$. The corresponding control rates were $37.3 \%$ and $36.4 \%$, respectively. In a stepwise logistic regression, the risk of uncontrolled hypertension was higher with older age ( +10 years, odds ratio (OR) $1.19, P=0.03$ ), female sex (OR $1.40, P=0.01$ ), obesity (OR $2.35, P=0.0002$ ) and heavy drinking ( $\geqslant 300 \mathrm{~g}$ per week, OR $2.18, P=0.0007$ ). In conclusion, in elderly Chinese, the prevalence of hypertension is high. In spite of reasonably high awareness and treatment rates, the control rate remains low, most likely due to an unhealthy lifestyle and the underuse and/or underdose of antihypertensive drugs.

Hypertension Research (2013) 36, 824-828; doi:10.1038/hr.2013.57; published online 13 June 2013

Keywords: awareness; elderly Chinese; prevalence; treatment

\section{INTRODUCTION}

Hypertension is an established modifiable risk factor for cardiovascular disease and mortality. ${ }^{1,2}$ The prevalence of hypertension consistently increases with age worldwide ${ }^{3,4}$ and is therefore high in the elderly. For various reasons, such as comorbid cardiovascular, ${ }^{5}$ renal $^{6}$ and metabolic disorders, ${ }^{7}$ the management of hypertension can be difficult, the control rate of hypertension is usually low and the risk of hypertension is high.

According to the 2002 National Nutrition and Health Survey (NNHS) in adult Chinese, the prevalence of hypertension in people of 60 years of age or older was $49.1 \%$, and the rates of awareness, treatment and control were $37.6 \%, 32.2 \%$, and $7.6 \%$, respectively. ${ }^{8}$ Uncontrolled hypertension in more than $90 \%$ of Chinese hypertensive patients is likely to be a major reason for the steady increase in the risk of mortality attributable to stroke and coronary heart disease over more than 20 years. ${ }^{9}$ Hypertension is becoming a major public health problem in China. ${ }^{10}$ With increasing longevity, rapid economic development and brisk urbanization, the problem of the management of hypertension, if not properly addressed, will become even worse in the next few years.

Not only does the pathophysiology of hypertension differ across populations, but the strategies for the management of hypertension can also be specific to populations. ${ }^{3,11}$ Barriers to improving the management of hypertension have to be investigated and identified in specific populations. We recently conducted a study in an elderly Chinese population, which was more than half hypertensive, living in a suburb of Shanghai. In the present cross-sectional analysis, we studied the prevalence, awareness, treatment and control of hypertension, and investigated the risk factors for uncontrolled hypertension. 


\section{METHODS}

\section{Study population}

Our study was conducted in the framework of the Chronic Disease Detection and Management in the Elderly ( $\geqslant 60$ years of age) Program supported by the municipal government of Shanghai. In a newly urbanized suburban town $30 \mathrm{~km}$ from the city center, we invited all residents of 60 years of age or older to participate in comprehensive examinations of cardiovascular disease and risk. The Ethics Committee of Ruijin Hospital, Shanghai Jiaotong University School of Medicine, approved the study protocol. All subjects provided written informed consent.

In the period from 2006 to 2008, a total of 4080 subjects (participation rate of $90 \%$ ) were enrolled. We excluded 131 subjects from this analysis because blood pressure measurements were not performed $(n=46)$ or because of other missing information $(n=85)$. Thus, the number of participants included in this analysis was 3949 .

\section{Field work}

One experienced physician measured each participant's blood pressure three times consecutively using a validated Omron 7051 oscillometric blood pressure monitor (Omron, Kyoto, Japan) after the subjects had rested for at least $5 \mathrm{~min}$ in the sitting position. These three blood pressure readings were averaged for analysis. The same physician administered a standardized questionnaire to collect information on medical history, smoking habits, alcohol consumption and the use of medications. A trained technician performed anthropometric measurements, including body height and weight. The body mass index was the weight in kilograms divided by the height in square meters.

Hypertension was defined as a sitting blood pressure of at least $140 \mathrm{~mm} \mathrm{Hg}$ systolic or $90 \mathrm{~mm} \mathrm{Hg}$ diastolic or as the use of antihypertensive drugs. We defined awareness of hypertension as a self-reported previous medical diagnosis of hypertension, the treatment of hypertension via the current use of antihypertensive drugs intended to lower blood pressure and the control of hypertension to a blood pressure lower than $140 \mathrm{~mm} \mathrm{Hg}$ systolic and $90 \mathrm{~mm}$ $\mathrm{Hg}$ diastolic in users of antihypertensive drugs. We defined moderate and heavy drinking as a weekly volume of alcohol consumption of 5-299 and $\geqslant 300 \mathrm{~g}$, respectively. ${ }^{12}$ We defined overweight and obesity as a body mass index of $25.0-29.9$ and $\geqslant 30 \mathrm{~kg} \mathrm{~m}^{-2}$, respectively. ${ }^{13}$

\section{Blood biochemistry}

Venous blood samples were drawn after overnight fasting for the measurement of plasma glucose concentration and serum concentrations of total cholesterol and triglycerides. Diabetes mellitus was defined as a plasma glucose level of at least $7.0 \mathrm{mmoll}^{-1}$ while fasting or $11.1 \mathrm{mmoll}^{-1}$ at any time or as the use of antidiabetic agents.

\section{Statistical methods}

For database management and statistical analysis, we used SAS software (version 9.13; SAS Institute, Cary, NC, USA). Mean values and proportions were compared by the Student's $t$-test and Fisher's exact test, respectively. Continuous measurements with a skewed distribution were normalized by logarithmic transformation and represented by geometric mean and $95 \%$ confidence interval (CI).

We studied determinants of uncontrolled hypertension using stepwise logistical regression, with the $P$-value set at 0.10 for independent variables to enter and stay in the model. We considered sex, age, obesity, current smoking, moderate and heavy alcohol consumption, diabetes mellitus, serum total cholesterol, the use of short-acting calcium channel blockers and the use of a combination of hydrochlorothiazide and reserpine or clonidine.

\section{RESULTS}

Characteristics of the participants

The 3949 participants (mean age of 68.3 years) included 2185 (55.3\%) women, $1208(30.6 \%)$ overweight subjects, 182 (4.6\%) obese subjects and $366(9.3 \%)$ diabetic patients. Men, compared with women, were slightly younger $(-0.8$ years, $P<0.0001$ ); had a lower body mass index $\left(-0.3 \mathrm{~kg} \mathrm{~m}^{-2}, \quad P=0.004\right)$; reported significantly higher $(P<0.0001)$ proportions of current smoking $(55.7 \%$ vs. $2.4 \%)$ and alcohol intake $(36.8 \%$ vs. $1.3 \%)$; and had a lower $(P<0.05)$ prevalence of overweight $(28.9 \%$ vs. $32.0 \%)$, obesity $(3.9 \%$ vs. $5.2 \%)$, and diabetes mellitus ( $8.1 \%$ vs. $10.1 \%$; Table 1$)$.

\section{Prevalence, awareness, treatment and control of hypertension}

Table 2 details the prevalence, awareness, treatment and control of hypertension by sex and age group. Overall, the prevalence of hypertension was $59.4 \%$. In the 2345 hypertensive subjects, 1701 (75.6\%) were aware of their disease condition, $1542(65.8 \%)$ were taking antihypertensive drugs and $572(22.7 \%)$ had their blood pressure controlled to a level below $140 / 90 \mathrm{~mm} \mathrm{Hg}$. In the 1542 treated hypertensive patients, the control rate was $37.1 \%$.

Men and women had a similar prevalence of hypertension $(59.5 \%$ vs. $59.4 \%, P=0.87)$. However, men, compared with women, had slightly lower rates of awareness $(71.2 \%$ vs. $74.6 \%, P=0.07)$ and treatment $(63.3 \%$ vs. $67.7 \%, P=0.03)$ and had a slightly higher control rate of hypertension in both all $(25.7 \%$ vs. $23.3 \%, P=0.08)$ and treated $(40.6 \%$ vs. $34.4 \%, P=0.01)$ hypertensive patients.

In men as well as women, the prevalence, awareness and treatment rates of hypertension were higher with older age $(P \leqslant 0.006)$, whereas the control rate of hypertension slightly decreased with older age $(P \leqslant 0.09)$. In addition, the control rate of hypertension in treated hypertensive patients was lower $(P \leqslant 0.03)$ in obese $(21.6 \%)$ than in overweight $(36.7 \%)$ and normal-weight subjects $(40.6 \%)$ and in heavy-drinking men $(28.2 \%)$ than in their moderate-drinking or nondrinking $(43.4 \%)$ counterparts $(42.7 \%$, Figure 1$)$.

Table 1 Characteristics of the study population by sex

\begin{tabular}{|c|c|c|c|}
\hline Characteristic & $\begin{array}{c}\text { Men } \\
(\mathrm{n}=1764)\end{array}$ & $\begin{array}{c}\text { Women } \\
(\mathrm{n}=2185)\end{array}$ & P-value \\
\hline Age (years) & $67.7 \pm 7.1$ & $68.7 \pm 7.5$ & $<0.0001$ \\
\hline Body mass index $\left(\mathrm{kg} \mathrm{m}^{-2}\right)$ & $23.6 \pm 3.4$ & $23.9 \pm 3.7$ & 0.004 \\
\hline Current smoking, $n(\%)$ & $973(55.7)$ & $52(2.4)$ & $<0.0001$ \\
\hline Alcohol intake, n (\%) & $642(36.8)$ & $28(1.3)$ & $<0.0001$ \\
\hline Moderate, $n(\%)$ & $282(16.4)$ & $20(0.9)$ & $<0.0001$ \\
\hline Heavy, $n(\%)$ & $360(20.4)$ & $8(0.4)$ & $<0.0001$ \\
\hline \multicolumn{4}{|l|}{ Blood pressure $(\mathrm{mm} \mathrm{Hg})$} \\
\hline Systolic & $137.8 \pm 19.6$ & $138.7 \pm 19.8$ & 0.14 \\
\hline Diastolic & $81.8 \pm 10.8$ & $80.5 \pm 10.5$ & 0.0001 \\
\hline Pulse rate (beats $\min ^{-1}$ ) & $74.9 \pm 12.0$ & $78.0 \pm 11.5$ & $<0.0001$ \\
\hline \multicolumn{4}{|l|}{ Biochemical measurements } \\
\hline $\begin{array}{l}\text { Plasma fasting glucose } \\
\left(\mathrm{mmoll}^{-1}\right)\end{array}$ & $5.31 \pm 1.12$ & $5.47 \pm 1.31$ & $<0.0001$ \\
\hline $\begin{array}{l}\text { Serum total cholesterol } \\
\left(\mathrm{mmoll}^{-1}\right)\end{array}$ & $5.51 \pm 1.42$ & $5.68 \pm 1.41$ & 0.0002 \\
\hline Serum triglycerides $\left(\mathrm{mmoll}^{-1}\right)$ & $\begin{array}{c}1.45(1.42 \\
1.47)\end{array}$ & $\begin{array}{c}1.57(1.54 \\
1.59)\end{array}$ & $<0.0001$ \\
\hline Diabetes mellitus, $n(\%)$ & $142(8.1)$ & $224(10.3)$ & 0.02 \\
\hline Overweight, $n(\%)$ & 509 (28.9) & $699(32.0)$ & 0.03 \\
\hline Obesity, $n(\%)$ & $68(3.9)$ & $114(5.2)$ & 0.04 \\
\hline
\end{tabular}

Values are anthrometric ( \pm s.d.) or geometric mean (95\% confidence interval), or the number of subjects $(\%)$. P-values are for comparisons between men and women. For definitions of moderate and heavy drinking, diabetes mellitus, overweight and obesity, see METHODS section. 

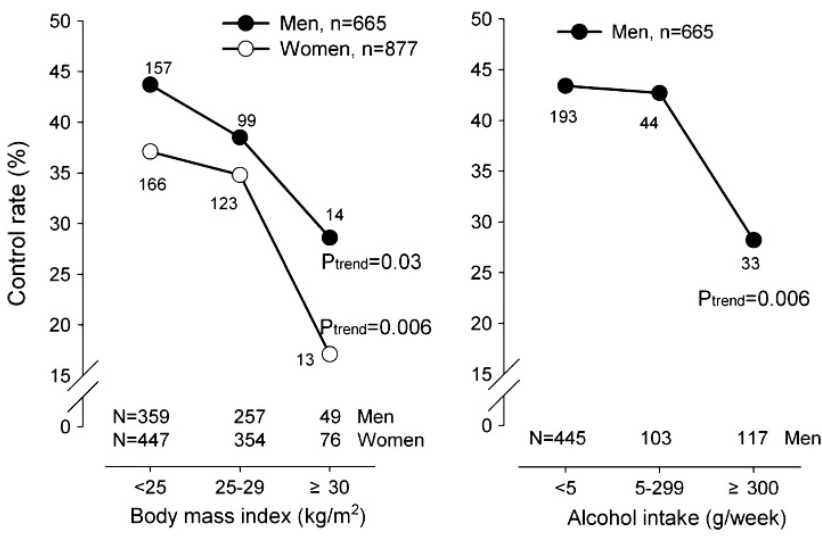

Figure 1 Control rate of hypertension in treated hypertensive patients by body mass index (left panel) and alcohol intake (right panel). The closed and open circles represent men and women, respectively. The number of treated hypertensive patients per group is given at the bottom, and the number of patients with controlled hypertension is given alongside the symbols.

Use of antihypertensive drugs and the control rate of hypertension Table 3 shows the control rate of hypertension according to the use of antihypertensive drugs in the 1542 treated hypertensive patients. In men and women combined, $77.6 \%$ of treated hypertensive patients used fixed-dose combinations of hydrochlorothiazide $(3.125-6.25 \mathrm{mg})$ and reserpine $(0.032-0.1 \mathrm{mg})$ or clonidine $(0.03 \mathrm{mg}, 75.0 \%)$ or of an angiotensin receptor blocker and hydrochlorothiazide $(n=1)$, or free combinations $(2.5 \%)$, and $22.4 \%$ used a monotherapy of calcium channel blockers $(14.1 \%)$, diuretics $(2.8 \%)$, angiotensin receptor blockers $(2.1 \%)$, angiotensin-converting enzyme inhibitors $(1.6 \%)$, $\beta$-blockers $(0.9 \%)$ or other antihypertensive drugs $(0.9 \%)$.

Men, compared with women, more frequently used a monotherapy of calcium channel blockers $(16.2 \%$ vs. $12.4 \%, P=0.03)$ and less frequently received a combination therapy of hydrochlorothiazide and reserpine or clonidine $(64.5 \%$ vs. $71.0 \%, P=0.02)$. However, the use of antihypertensive drugs was similar between obese subjects and overweight and normal-weight subjects $(P \geqslant 0.87)$ and between heavy-drinking men and moderate-drinking and nondrinking men $(P \geqslant 0.61)$

Overall, the control rate of hypertension was similar across various classes of antihypertensive drugs $(P \geqslant 0.21$, Table 3$)$. Increasing the frequency of the drug usage per day slightly but nonsignificantly $(P \geqslant 0.18)$ increased the control rate of hypertension for a monotherapy of short-acting calcium channel blockers (from $35.4 \%$ once daily to $37.4 \%$ two times daily and $41.4 \%$ three times daily) and for a combination therapy of hydrochlorothiazide and reserpine or clonidine (from $34.5 \%$ once daily to $38.2 \%$ two times daily and $40.0 \%$ three times daily).

\section{Risk factors for uncontrolled hypertension}

For the treated hypertensive patients, we performed a stepwise logistical regression to investigate the determinants of uncontrolled hypertension. The risk of uncontrolled hypertension was higher with older age $(+10$ years, odds ratio (OR) 1.19 , 95\% CI: $1.02-1.38$, $P=0.03$ ), female sex (OR 1.40, 95\% CI: $1.07-1.84, P=0.01$ ), obesity (OR 2.35, 95\% CI: $1.50-3.69, P=0.0002$ ) and heavy drinking $(\geqslant 300$ g per week, OR 2.18, 95\% CI: 1.39-3.44, $P=0.0007$; Table 4).

In further gender-specific analyses, we found that the risk of uncontrolled hypertension was higher with obesity (OR 1.85, 95\% CI $0.97-3.52, P=0.06$ ) and heavy drinking (OR 1.98, 95\%: CI 1.28-3.01, 


\begin{tabular}{|c|c|c|c|c|}
\hline & \multicolumn{2}{|c|}{ Men $(n=665)$} & \multicolumn{2}{|c|}{ Women $(n=877)$} \\
\hline & $\begin{array}{l}\text { Number of } \\
\text { patients (\%) }\end{array}$ & $\begin{array}{l}\text { Control } \\
\text { rate (\%) }\end{array}$ & $\begin{array}{l}\text { Number of } \\
\text { patients (\%) }\end{array}$ & $\begin{array}{l}\text { Control } \\
\text { rate (\%) }\end{array}$ \\
\hline Monotherapy & $163(24.5)$ & 40.5 & $183(20.1)$ & 34.4 \\
\hline Diuretics & $20(3.0)$ & 40.0 & $23(2.6)$ & 34.8 \\
\hline$\beta$-Blockers & $6(0.9)$ & 50.3 & $8(0.9)$ & 37.5 \\
\hline Short-acting calcium channel blockers & $108(16.2)$ & 38.9 & $109(12.4)^{*}$ & 33.9 \\
\hline Once daily & $58(53.7)$ & 36.2 & $55(50.5)$ & 32.7 \\
\hline Two times daily & $44(40.7)$ & 40.9 & $45(41.3)$ & 35.6 \\
\hline$\geqslant 3$ Times daily & $6(5.6)$ & 50.0 & $9(8.2)$ & 33.3 \\
\hline Angiotensin-converting enzyme inhibitors & $12(1.8)$ & 41.7 & $13(1.5)$ & 38.5 \\
\hline Angiotensin receptor blockers & $13(2.0)$ & 46.2 & $20(2.3)$ & 35.0 \\
\hline Other antihypertensive drugs & $4(0.6)$ & 50.0 & $10(1.1)$ & 30.0 \\
\hline Combination therapy & $502(75.5)$ & 41.0 & $694(79.1)$ & $34.7^{*}$ \\
\hline Fixed-dose combinations of hydrochlorothiazide plus reserpine or clonidine & $480(72.2)$ & 40.8 & $677(77.2)$ & $34.7^{*}$ \\
\hline Alone & $429(64.5)$ & 41.5 & $623(71.0)^{*}$ & $34.3^{*}$ \\
\hline Once daily & $163(38.0)$ & 39.2 & $224(36.0)$ & 32.6 \\
\hline Two times daily & $197(45.9)$ & 41.1 & $306(49.1)$ & 35.0 \\
\hline$\geqslant 3$ Times daily & $69(16.1)$ & 47.8 & $93(14.9)$ & 36.6 \\
\hline Plus others & $51(7.8)$ & 35.3 & $54(6.2)$ & 38.9 \\
\hline Fixed-dose combination of angiotensin receptor blocker plus hydrochlorothiazide & $1(0.2)$ & - & 0 & - \\
\hline Free combinations & $21(3.2)$ & 47.6 & $17(1.9)$ & 35.3 \\
\hline
\end{tabular}

Values are number of subjects with the percentage of column total within the parentheses or control rate of hypertension in patients on a specific antihypertensive regimen.

${ }^{*} P \leqslant 0.05$ vs. men.

Table 4 Determinants of uncontrolled hypertension in stepwise logistic regression

\begin{tabular}{lcl}
\hline & $\begin{array}{c}\text { Odds ratio } \\
\text { (95\% confidence interval) }\end{array}$ & P-value \\
\hline Age $(+10$ years) & $1.19(1.02-1.38)$ & 0.03 \\
Women (vs. men) & $1.40(1.07-1.84)$ & 0.01 \\
Obesity $\left(\geqslant 30 \mathrm{~kg} \mathrm{~m}^{-2}\right)$ & $2.35(1.50-3.69)$ & 0.0002 \\
Heavy drinking $(\geqslant 300$ g per week) & $2.18(1.39-3.44)$ & 0.0007 \\
\hline
\end{tabular}

In the analysis, we considered sex, age, obesity, current smoking, alcohol intake, diabetes mellitus, serum total cholesterol, the use of short-acting calcium channel blockers and the use of combination of hydrochlorothiazide plus reserpine or clonidine to enter and stay in the model with a $P$-value set at 0.10

$P=0.002)$ in men and with obesity (OR 2.91, 95\% CI: $1.57-5.41$, $P=0.0007)$ in women.

\section{DISCUSSION}

Our study in an elderly Chinese population demonstrated that very few hypertensive patients used the guidelines recommended newer, long-acting antihypertensive drugs. This underuse or underdose might explain the low control rate of hypertension in treated hypertensive patients. In addition, several lifestyle factors, such as obesity and alcohol intake, also render hypertension difficult to control.

In comparison with the elderly ( $\geqslant 60$ years of age) subgroup of the 2002 NNHS, ${ }^{8}$ the prevalence $(59.4 \%$ vs. $49.1 \%)$, awareness $(75.6 \%$ vs. $37.6 \%)$, treatment $(65.8 \%$ vs. $32.2 \%)$ and control $(22.7 \%$ vs. $7.6 \%)$ of hypertension were higher in our study. However, when we scrutinize the difference between our study and the national survey, the major distinction in the management of hypertension is the approximately onefold higher rate of awareness of hypertension in our study.
This difference made substantial contributions to the higher rate of the treatment and control of hypertension in our study. Our study was a few years later than the national survey and was conducted in a single town near one of the most industrialized cities in China. Both the time and location factors may account for the difference between our study and the most recent national survey. ${ }^{8}$

In spite of the significant improvement in the management of hypertension in our study, there is still a large lag when compared with the National Health and Nutrition Examination Survey (NHANES) administered from 1999 to 2004 in the United States, ${ }^{14}$ in which the prevalence, awareness, treatment and control of hypertension in the elderly ( $\geqslant 60$ years of age) subgroup were $66.3 \%, 81.0 \%, 73.4 \%$ and $36.7 \%$, respectively. The results of our study suggest that the gap is mainly attributable to the inappropriate use of antihypertensive drugs. In our study, most patients used a combination therapy of underdosed hydrochlorothiazide and reserpine or clonidine or a monotherapy of short-acting antihypertensive drugs. These drugs should be taken multiple times per day, but in our elderly subjects, these drugs were often taken once daily. Both the 2005 and 2010 Chinese hypertension guidelines recommend using long-acting antihypertensive drugs. ${ }^{15,16}$ The lowcost, generic forms of long-acting antihypertensive drugs have also been available on the Chinese market for decades. Most antihypertensive drugs are on the reimbursement list of the public health insurance in the geographical area of our study. The major reason for the inappropriate use of antihypertensive drugs is the lack of qualified physicians in suburban and rural areas. For this reason, the guideline recommendations have not yet been implemented.

In addition to the inappropriate use of antihypertensive drugs, obesity and heavy drinking could also be reasons for uncontrolled hypertension. These unhealthy lifestyle factors are known to cause hypertension and render hypertension resistant to antihypertensive 
therapy. ${ }^{17,18}$ Regarding the very low control rate of hypertension in obese people and heavy drinkers in our study, it is possible that hypertension is secondary to these risk factors and can only be controlled when these risk factors are properly modified. ${ }^{19,20}$ To a certain extent, it is unexpected that diabetes mellitus was not associated with uncontrolled hypertension. In our study, the treatment rate was higher in diabetic patients than non-diabetic patients $(57.4 \%$ vs. $37.2 \%, P<0.0001)$. We therefore speculate that hypertension might have been diagnosed and/or treated earlier and hence better controlled in diabetic than in non-diabetic subjects.

Our study should be interpreted within the context of its strengths and limitations. Our study was conducted in a newly urbanized population. China is now in a rapid urbanization period. In the past decades, a large number of rural people, such as our study subjects, immigrated to cities or were locally urbanized. In the coming decades, more people from rural areas will follow this path. Our study will therefore provide useful information on the disease and health status of newly urbanized people. In addition, our study had a high participation rate $(90 \%)$ and a low exclusion rate $(3 \%)$. Our study was conducted in a single town near the most industrialized Chinese city, Shanghai. Our study could be less representative of the Chinese population than a multicenter study, especially in terms of various rates of hypertension. However, this limitation in representation has little influence on the validity of our findings on the risk factors for uncontrolled hypertension. In addition, we measured blood pressure only during a single visit, which could cause overestimation.

In conclusion, in elderly Chinese, the prevalence of hypertension is high. In spite of a reasonably high awareness and treatment rate, the control rate remains low, most likely due to the underuse or underdose of antihypertensive drugs and an unhealthy lifestyle. Our ongoing and future research in this elderly population will monitor changes in the management of hypertension and investigate these changes' relevance to cardiovascular prevention.

\section{CONFLICT OF INTEREST}

The authors declare no conflict of interest.

\section{ACKNOWLEDGEMENTS}

We gratefully acknowledge the voluntary participation of all study subjects and the technical assistance of the physicians and nurses of Zhaoxiang Community Health Centre (Qingpu District, Shanghai). We also appreciate the expert assistance of Jie Wang, Li Zheng, Wei-Zhong Zhang and Yi Zhou (The Shanghai Institute of Hypertension, China). This study was financially supported by grants from the National Natural Science Foundation of China (Grants 30871360, 30871081, 81170245 and 81270373); the Ministry of Science and Technology (2006BAI01A03 and a grant for China-European Union collaborations (1012)) and the Ministry of Education (NCET-09-0544), Beijing, China; the Shanghai Commissions of Science and Technology (Grants 07JC14047 and 11QH1402000 and the 'Rising Star' program 06QA14043) and of Education (Grant 07ZZ32 and the 'Dawn' project 08SG20); the Shanghai
Bureau of Health (Grants 2009Y111 and XBR2011004); Shanghai Jiaotong University School of Medicine (a grant for Distinguished Young Investigators awarded to Yan Li); and the European Union (Grants LSHM-CT-2006-037093 and HEALTH-F4-2007-201550).

1 Kannel WB. Blood pressure as a cardiovascular risk factor: prevention and treatment. JAMA 1996; 275: 1571-1576.

2 Staessen JA, Wang J, Bianchi G, Birkenhäger WH. Essential hypertension. Lancet 2003; 361: 1629-1641.

3 Kearney PM, Whelton M, Reynolds K, Muntner P, Whelton PK, He J. Global burden of hypertension: analysis of worldwide data. Lancet 2005; 365: 217-223.

4 Ostchega Y, Dillon CF, Hughes JP, Carroll M, Yoon S. Trends in hypertension prevalence, awareness, treatment, and control in older U.S. adults: data from the Nationa Health and Nutrition Examination Survey 1988 to 2004. J Am Geriatr Soc 2007; 55: 1056-1065.

5 Kannel WB. Risk stratification in hypertension: new insights from the Framingham Study. Am J Hypertens 2000; 13: S3-S10.

6 Segura J, Ruilope LM, Zanchetti A. On the importance of estimating renal function for cardiovascular risk assessment. J Hypertens 2004; 22: 1635-1639.

7 Vasan RS, Beiser A, Seshadri S, Larson MG, Kannel WB, D'Agostino RB, Levy D. Residual lifetime risk for developing hypertension in middle-aged women and men: The Framingham Heart Study. JAMA 2002; 287: 1003-1010.

8 Li LM, Rao KQ, Kong LZ, Yao CH, Xiang HD, Zhai FY, Ma GS, Yang XG. Technical Working Group of China National Nutrition and Health Survey. A description on the Chinese national nutrition and health survey in 2002. Chin J Epidemiol 2005; 26: 478-484. in Chinese.

9 Hu SS, Kong LZ, Gao RL, Zhu ML, Wang W, Wang YJ, Wu ZS, Chen WW, Liu MB. Editorial Board. Outline of the report on cardiovascular disease in China, 2010. Biomed Environ Sci 2012; 25: 251-256.

10 He L, Tang X, Song Y, Li N, Li J, Zhang Z, Liu J, Yu L, Xu H, Zhang J, Hu Y. Prevalence of cardiovascular disease and risk factors in a rural district of Beijing, China: a population-based survey of 58,308 residents. BMC Public Health 2012; 12: 34

11 Martiniuk AL, Lee CM, Lawes CM, Ueshima H, Suh I, Lam TH, Gu D, Feigin V, Jamrozik K, Ohkubo T, Woodward M. Asia-Pacific Cohort Studies Collaboration. Hypertension: its prevalence and population-attributable fraction for mortality from cardiovascular disease in the Asia-Pacific region. J Hypertens 2007; 25: 73-79.

12 McFadden CB, Brensinger CM, Berlin JA, Townsend RR. Systematic review of the effect of daily alcohol intake on blood pressure. Am J Hypertens 2005; 18: 276-286.

13 Expert Panel on the Identification, Evaluation, and Treatment of Overweight in Adults. Clinical guidelines on the identification, evaluation, and treatment of overweight and obesity in adults: executive summary. Am J Clin Nutr 1998; 68: 899-917.

14 Ong KL, Cheung BM, Man YB, Lau CP, Lam KS. Prevalence, awareness, treatment, and control of hypertension among United States adults 1999-2004. Hypertension 2007; 49. $69-75$.

15 Committee for Revision of Chinese Guidelines for Prevention and Treatment of Patients with Hypertension. Chinese guidelines for prevention and treatment of patients with hypertension. Chin J Hypertens 2005; 134: 2-41 [in Chinese].

16 Writing Group of 2010 Chinese Guidelines for the Management of Hypertension. 2010 Chinese guidelines for the management of hypertension. Zhonghua Xin Xue Guan Bing Za Zhi 2011; 39: 579-615 [in Chinese].

17 Li Y, Wang JG, Gao PJ, Wang GL, Qian YS, Zhu DL, Staessen JA. Interaction between alcohol intake and body mass index in relation to blood pressure in HAN and SHE Chinese. Am J Hypertens 2006; 19: 448-453.

18 Vasan RS, Larson MG, Leip EP, Kannel WB, Levy D. Assessment of frequency of progression to hypertension in non-hypertensive participants in the Framingham Heart Study: a cohort study. Lancet 2001; 358: 1682-1686.

19 Mattila R, Malmivaara A, Kastarinen M, Kivelä SL, Nissinen A. Effectiveness of multidisciplinary lifestyle intervention for hypertension: a randomised controlled trial. J Hum Hypertens 2003; 17: 199-205.

20 Gupta AK, Nasothimiou EG, Chang CL, Sever PS, Dahlöf B, Poulter NR. ASCOT investigators. Baseline predictors of resistant hypertension in the Anglo-Scandinavian Cardiac Outcome Trial (ASCOT): a risk score to identify those at high-risk. J Hypertens 2011; 29: 2004-2013. 